\title{
Is Ramosetron Really Useful to Treat Diabetic Diarrhea With Rapid Small Bowel Transit?: Author's Reply
}

TO THE EDITOR: I appreciate for Dr. Lee's comments. ${ }^{1}$ The 5-hydroxytryptamine (5-HT) receptors (the original 5-HT M receptor) are distributed widely in both the gastrointestinal (GI) tract and the central nerve system, and result in increased intestinal secretion and alteration of peristaltic activity. The action of $5-\mathrm{HT}_{3}$ receptor antagonists $\left(5-\mathrm{HT}_{3} \mathrm{RAs}\right)$ to modify contraction-relaxation responses would be dependent on the relative balance of excitatory-inhibitory tone. Therefore, 5- $\mathrm{HT}_{3} \mathrm{RAs}$ might reduce motor activity in the presence of an abnormally increased basal activity.

Ramosetron, a selective $5-\mathrm{HT}_{3}$ receptor antagonist, has been confirmed to have an inhibitory effect on lower GI transit. This drug has been known to be effective for diarrhea predominant irritable bowel syndrome in both animal and clinical studies. But its effects and mechanisms on the upper GI tract (stomach and small intestine) have not been verified.

Classic sympathetic, parasympathetic autonomous nervous system, and the enteric nervous system (ENS) are important for the regulation of enteric function. Diabetes results in abnormalities of the ENS, such as loss of neurons containing nitric oxide synthase, which mediates GI tract relaxation, and an increase in the serotonin contents, which regulate GI tract contraction. An imbalance between the inhibitory and excitatory ENS could be one of the causes of diabetic diarrhea. The $5-\mathrm{HT}_{3}$ receptor antagonist inhibits the excitatory neurons of ENS thus plays a role in regulating a balance of the ENS components in diabetic patients. ${ }^{2,3}$ Based on these mechanisms, Murao and Hosokawa ${ }^{2}$ reported the effect of ramosetron, which was developed as an antiemetic drug for cancer chemotherapy and for the treatment of diabetic diarrhea.
In our study, the effect was well demonstrated by its inhibitory effects on accelerated GI transit caused by 5-HT, thyrotropin-releasing hormone and mustard oil. ${ }^{3}$ However, Hirata et $\mathrm{al}^{4}$ showed recently that ramosetron significantly inhibited the delayed gastric emptying in a corticotrophin releasing factor and soybean oil-induced rat model, in comparison with anti-diarrheal agent and spasmolytics.

We should consider the differences in the dose of ramosetron and the action mechanism of the substance that caused changes in altered GI transit. There were conflicting results from animal experiments on the same drug. ${ }^{3,4}$ This could be an evidence presenting the different treatment effects of ramosetron in patients with autonomic neuropathy, diabetic diarrhea and gastroparesis.

Yoo Mi Park and Hyojin Park

Department of Internal Medicine, Gangnam Severance Hopsital, Yonsei University College of Medicine, Seoul, Korea

1. Lee TH. Is ramosetron really useful to treat diabetic diarrhea with rapid small bowel transit? J Neurogastroenterol Motil 2013;19:270271.

2. Murao S, Hosokawa H. Serotonin 5-HT3 receptor antagonist for treatment of severe diabetic diarrhea. Diabetes Care 2010;33:e38.

3. Park YM, Lee YJ, Lee YH, Kim TI, Park H. Effects of ramosetron on gastrointestinal transit of Guinea pig. J Neurogastroenterol Motil 2013;19:36-41.

4. Hirata T, Keto Y, Yamano M, Yokoyama T, Sengoku T, Seki N. Inhibitory effect of ramosetron on CRF- and soybean oil-induced delays in gastric emptying in rats. J Gastroenterol Hepatol 2012;27: 1505-1511.

\section{Conflicts of interest: None.}

